\title{
Brain insulin action augments hepatic glycogen synthesis without suppressing glucose production or gluconeogenesis in dogs
}

\author{
Christopher J. Ramnanan, ${ }^{1}$ Viswanathan Saraswathi, ${ }^{1}$ Marta S. Smith, ${ }^{1}$ \\ E. Patrick Donahue, ${ }^{1}$ Ben Farmer, ${ }^{1}$ Tiffany D. Farmer, ${ }^{1}$ Doss Neal, ${ }^{1}$ Philip E. Williams, ${ }^{2}$ \\ Margaret Lautz, ${ }^{1}$ Andrea Mari, ${ }^{3}$ Alan D. Cherrington, ${ }^{1}$ and Dale S. Edgerton' \\ 1Department of Molecular Physiology and Biophysics and 2Division of Surgical Research, Vanderbilt University School of Medicine, \\ Nashville, Tennessee, USA. ${ }^{3}$ Institute of Biomedical Engineering, National Research Council, Padova, Italy.
}

\begin{abstract}
In rodents, acute brain insulin action reduces blood glucose levels by suppressing the expression of enzymes in the hepatic gluconeogenic pathway, thereby reducing gluconeogenesis and endogenous glucose production (EGP). Whether a similar mechanism is functional in large animals, including humans, is unknown. Here, we demonstrated that in canines, physiologic brain hyperinsulinemia brought about by infusion of insulin into the head arteries (during a pancreatic clamp to maintain basal hepatic insulin and glucagon levels) activated hypothalamic Akt, altered STAT3 signaling in the liver, and suppressed hepatic gluconeogenic gene expression without altering EGP or gluconeogenesis. Rather, brain hyperinsulinemia slowly caused a modest reduction in net hepatic glucose output (NHGO) that was attributable to increased net hepatic glucose uptake and glycogen synthesis. This was associated with decreased levels of glycogen synthase kinase $3 \beta$ (GSK $3 \beta$ ) protein and mRNA and with decreased glycogen synthase phosphorylation, changes that were blocked by hypothalamic PI3K inhibition. Therefore, we conclude that the canine brain senses physiologic elevations in plasma insulin, and that this in turn regulates genetic events in the liver. In the context of basal insulin and glucagon levels at the liver, this input augments hepatic glucose uptake and glycogen synthesis, reducing NHGO without altering EGP.
\end{abstract}

\section{Introduction}

The ability of insulin to suppress hepatic glucose production (HGP) in vivo has been well defined (1), but the role of the CNS in this suppression remains controversial. The brain is an insulinsensitive organ, and brain insulin action has been shown to regulate whole-body glucose metabolism, in part, by altering pancreatic insulin and glucagon secretion (2-4). Obici et al., on the other hand, demonstrated that i.c.v. infusion of insulin could reduce glucose production by approximately $30 \%$ in the rodent, even when insulin was clamped at a basal level, by infusing it into a peripheral vein while infusing somatostatin to inhibit endogenous secretion (5). It should be noted that this clamp protocol would have eliminated the approximately 3 -fold insulin gradient that normally exists between the portal vein and arterial blood and created insulin deficiency at the liver. An elevation in HGP secondary to hepatic hypoinsulinemia was prevented by the lack of glucagon replacement during the clamp. Thus, the effect of brain insulin action was observed when the liver was deficient in 2 of its primary glucoregulatory signals. Subsequent studies, many of which used a similar peripheral insulin clamp design, suggested that the mechanism by which insulin (and other factors) acts within the hypothalamus to suppress HGP requires modification of vagal input to the liver (6-8), phosphorylation of hepatic STAT3 (9), and suppression of

Authorship note: Alan D. Cherrington and Dale S. Edgerton are co-senior authors. Conflict of interest: The authors have declared that no conflict of interest exists. Citation for this article: J Clin Invest. 2011;121(9):3713-3723. doi:10.1172/JCI45472. gluconeogenic gene expression (8-13). Although gluconeogenic gene expression was typically used as a surrogate for gluconeogenesis, one group was able to show that centrally mediated inhibition of HGP was caused by a decrease in gluconeogenesis, although it required a number of hours to be seen $(6,10-12)$, consistent with regulation at the genetic level. Based on the collective observations in rodents, it has been concluded that insulin signaling in the brain is a physiologically important component of the acute effect of insulin on HGP in vivo (14). Furthermore, aberrant hypothalamic insulin signaling has been suggested to contribute to the disruption of glucose homeostasis associated with the diabetic state, and thus may be a target with therapeutic potential (14-16).

Data from studies in humans and large animals, however, suggest that insulin signaling in the hypothalamus may not play a role in the control of HGP in such species. The regulation of HGP by insulin is maintained in human recipients of liver transplants and in dogs subjected to hepatic denervation $(17,18)$. Moreover, HGP in dogs is exquisitely sensitive to small changes in portal vein insulin levels, even when the arterial plasma insulin level (and thus the brain insulin level) remains basal (19). In fact, insulin's direct hepatic effect has been established as being dominant (relative to all of its actions in nonhepatic tissues) in regulating HGP (20). It is possible that the suppression of HGP by i.c.v. insulin in rodents was only apparent because of the context in which it was studied (i.e., supraphysiological brain insulin levels, nonphysiologic access to CNS insulin receptors, and/or hepatic hypoinsulinemia and glucagonopenia). Thus, our aim was to determine whether the 

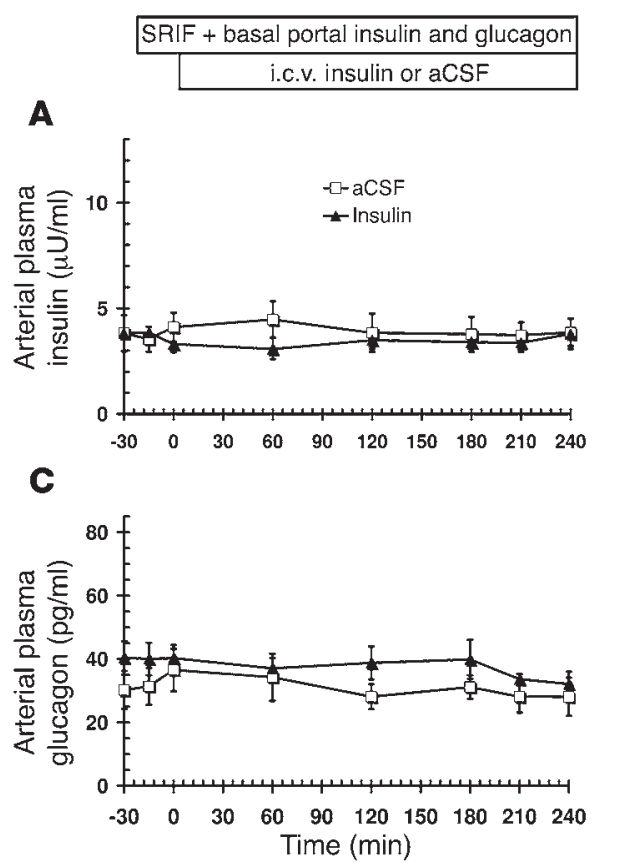

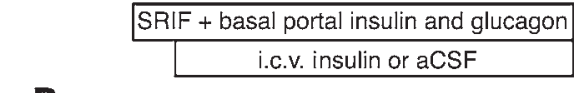

\section{B}

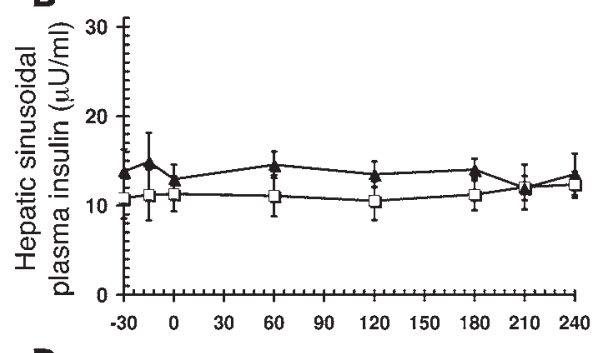

D

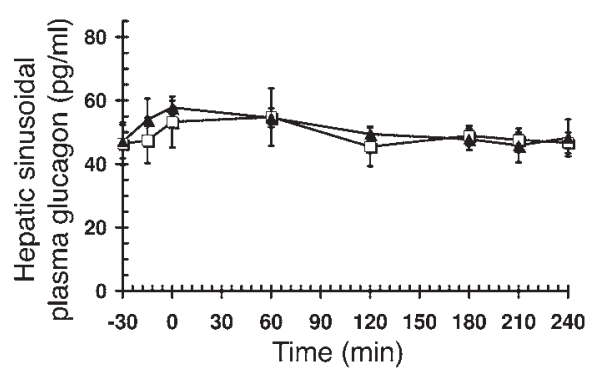

\section{Figure 1}

Plasma insulin and glucagon concentrations in dogs subjected to the i.c.v. insulin protocol. As illustrated above the graphs, 18-hour fasted conscious dogs received peripheral infusion of somatostatin (SRIF) and were maintained on a pancreatic clamp at basal levels of hepatic insulin and glucagon, then exposed to i.c.v. infusion of either aCSF or aCSF plus insulin. (A) Arterial plasma insulin. (B) Hepatic sinusoidal plasma insulin. (C) Arterial plasma glucagon. (D) Hepatic sinusoidal plasma glucagon. Values are mean \pm SEM. $n=5$ per group. insulin-brain-liver signaling pathway is intact and relevant to the acute (<4 hours) suppression of HGP in conscious canines. In the first set of experiments, we created pharmacological brain hyperinsulinemia by i.c.v. insulin infusion in dogs undergoing a portal vein basal hormone clamp. Although these experiments confirmed that in dogs, as in rodents, hypothalamic insulin signaling can mediate transcriptional events within the liver, they left unclear the physiologic relevance of this insulin-brain-liver axis as a result of the nonphysiologic nature of i.c.v. insulin administration. Thus, in a second protocol, we infused insulin directly into the arteries that perfuse the brain, thereby creating a physiologic rise (10-fold) in brain insulin via its physiological route of delivery, while again maintaining basal insulin and glucagon levels at the liver. To confirm that any observed effects were the result of brain insulin action, in a separate group we blocked brain insulin signaling by i.c.v. infusion of a PI3K inhibitor.

\section{Results}

Insulin delivery i.c.v. In the i.c.v. protocol, arterial and hepatic sinusoidal insulin and glucagon levels were clamped at basal values in 18-hour fasted animals by peripheral infusion of somatostatin and infusion of the pancreatic hormones into the portal vein (Figure 1), after which either artificial cerebrospinal fluid (aCSF) or insulin in aCSF was infused into the third ventricle. Insulin infusion i.c.v. created a marked increase in CSF insulin levels (sampled after the termination of the study) relative to levels in the aCSF group $(69.5 \pm 9.3 \mu \mathrm{U} / \mathrm{ml}$ vs. $0.3 \pm 0.1 \mu \mathrm{U} / \mathrm{ml})$. There were no differences in arterial plasma nonesterified fatty acid (NEFA), cortisol, or catecholamine levels (Supplemental Table 1; supplemental material available online with this article; doi:10.1172/JCI45472DS1), nor were there differences in the blood levels of any gluconeogenic substrate (Supplemental Table 2).

Euglycemia was effectively maintained by low rates of glucose infusion in both groups (Figure 2, A and B). Net hepatic glucose output (NHGO), tracer-derived endogenous glucose production (EGP), glucose rate of disappearance ( $\mathrm{Rd}$; a measure of glucose utilization), and glucose clearance tended to decrease relative to the basal period in the aCSF group as the animals progressed into the fasted state (Figure 2, C-F). Infusion of insulin into the third ventricle had no effect on EGP, glucose Rd, or glucose clearance. By the fourth hour, NHGO was slightly lower and the glucose infusion rate was slightly higher in the i.c.v. insulin group, but the differences were not significant.

At the molecular level, i.c.v. insulin infusion did not alter hepatic Akt or FOXO1 phosphorylation (Figure 3, A and B). On the other hand, it did activate several components of the canonical insulinhypothalamic-liver signaling axis established in rodents. Relative to control animals, i.c.v. insulin treatment resulted in 3.6- and 2.9-fold elevations of hypothalamic phospho-Akt and hepatic phospho-STAT3, respectively (Figure 3, C and D), along with $58 \%, 43 \%$, and $30 \%$ reductions in hepatic PEPCK, G6Pase, and PC mRNA levels, respectively (Figure $3 \mathrm{E}$ ). These changes in gene transcription resulted in small but nonsignificant reductions in PEPCK and PC protein levels (12\%-15\%; $P<0.10$; Figure $3 \mathrm{~F})$.

Thus, in this first set of experiments, we confirmed that the insulin-brain-liver pathway delineated in rodents was conserved in 18hour fasted canines and was activated by i.c.v. administration of insulin in the presence of basal hepatic insulin and glucagon levels. While i.c.v. insulin suppressed gluconeogenic gene expression in the liver, it did not significantly alter HGP.

Insulin delivery via carotid and vertebral arteries. Having shown this central signaling mechanism to exist in the dog, we next assessed whether a physiologic increase in brain insulin could bring about signaling changes in the liver and alter hepatic glucose metabolism in the context of a baseline pancreatic clamp (basal hepatic insulin and glucagon). This required the infusion of insulin bilaterally into the arteries perfusing the brain (carotid and vertebral). Unlike i.c.v. infusion, head artery insulin infusion created brain hyperinsulinemia that was physiologic both in magnitude ( 10-fold) and route of delivery (plasma) while still maintaining basal insulin levels in the hepatic sinusoids. We also extended the fast to 42 hours in order to increase the relative contribution of gluco- 

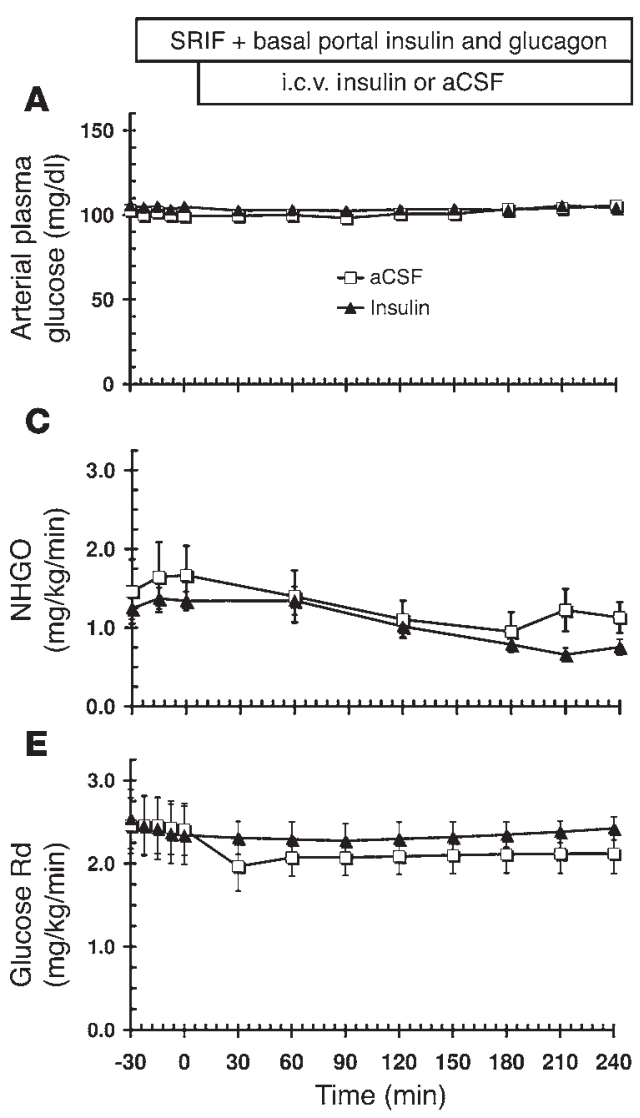

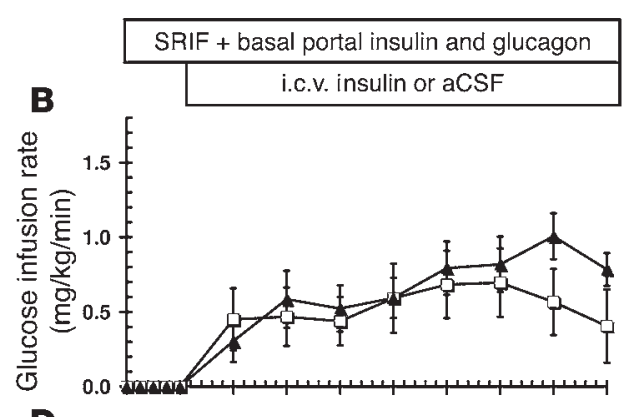

D
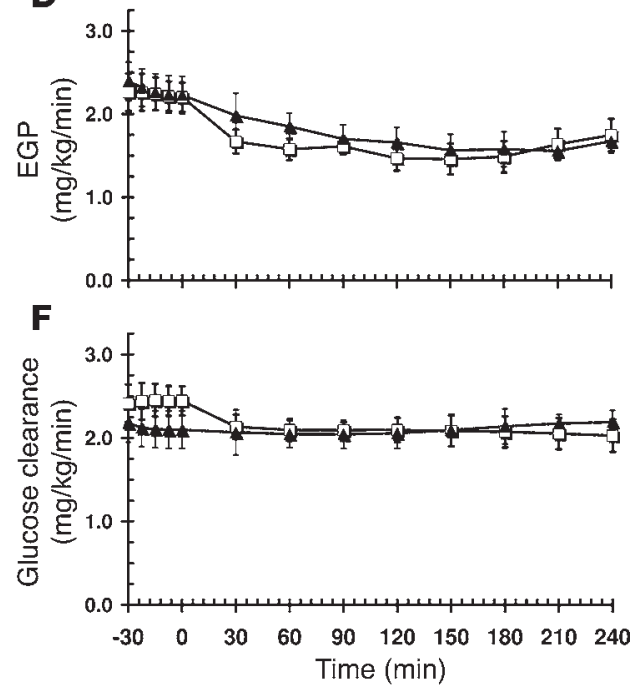

Figure 2

Effect of the i.c.v. insulin protocol on glucose flux. Insulin did not significantly alter arterial plasma glucose (A), glucose infusion rate (B), NHGO (C), EGP (D), glucose Rd (E), and glucose clearance (F) relative to aCSF controls. Values are mean \pm SEM. $n=5$ per group.

neogenesis to HGP and thus enhance our ability to detect the effect of a change in gluconeogenesis, should one occur. Concurrent i.c.v. administration of the PI3K inhibitor LY294002 (LY) or aCSF was performed to confirm that the effects of brain insulin action on the liver were the result of hypothalamic insulin signaling. Thus, the head artery insulin infusion protocol used 4 distinct treatment groups: saline plus i.c.v. aCSF control (referred to herein as CTR), saline plus i.c.v. LY (CTR+LY), selective head hyperinsulinemia plus i.c.v. aCSF (HI), and selective head hyperinsulinemia plus i.c.v. LY (HI+LY).

Hepatic sinusoidal and hepatic vein plasma insulin levels remained basal throughout the experiment in all 4 groups (Figure 4, $A$ and B). Arterial and jugular vein insulin concentrations also remained at basal levels in the CTR and CTR+LY groups (Figure 4, $\mathrm{C}$ and $\mathrm{D})$. Conversely, insulin infusion into the head arteries brought about 3 - and 10-fold increases in arterial (non-head) and jugular vein insulin levels, respectively. Since the brain does not extract detectable amounts of insulin (21), the jugular vein insulin concentrations can be taken to reflect arterial insulin levels perfusing the brain. Glucagon was replaced at basal levels in all animals (Figure 4E). The decreases in circulating NEFA levels and net hepatic NEFA uptake, which would normally occur as a result of the arterial hyperinsulinemia $(19,22-25)$, were prevented by infusion of Intralipid plus heparin (initiated at 0 minutes) in the HI and $\mathrm{HI}+\mathrm{LY}$ groups. As a result, arterial NEFA concentrations, as well as net hepatic NEFA uptake, were maintained near basal val- ues in all groups (Figure 4F and Supplemental Figure 1). Arterial glycerol concentrations and net hepatic glycerol uptake were basal in CTR and CTR+LY animals (Supplemental Figure 1), but rose slightly when Intralipid was given (HI and $\mathrm{HI}+\mathrm{LY}$ ). Arterial concentrations of catecholamines and cortisol were similar and basal in all groups (Supplemental Table 3). Likewise, arterial levels and net hepatic balances of gluconeogenic amino acids and lactate did not differ between groups (Supplemental Table 4).

Euglycemia was maintained in all groups by i.v. glucose infusion (Figure 5A). We assessed glucose flux in vivo by measuring NHGO (the difference between HGP and hepatic glucose uptake) and the net rate of G6P formation from both the gluconeogenic/ glycolytic and the glycogenolytic/glycogen synthetic pathways (net hepatic gluconeogenic [NHGNG] and net hepatic glycogenolytic [NHGLY] flux, respectively). We also infused $\left[3-{ }^{3} \mathrm{H}\right]$ glucose and ${ }^{2} \mathrm{H}_{2} \mathrm{O}$ to allow us to calculate EGP and to estimate both the gluconeogenic and glycogenolytic contribution to this production rate. There were no differences in NHGO or EGP between the basal sampling period ( -90 to -60 minutes) and the period during which i.c.v. infusion of either aCSF or LY was initiated (-60 to 0 minutes). Therefore, the basal control period was considered to be -90 to 0 minutes. NHGO rates during this period were $1.17 \pm 0.18,1.48 \pm 0.14$, $1.60 \pm 0.13$, and $1.22 \pm 0.08 \mathrm{mg} / \mathrm{kg} / \mathrm{min}$ in CTR, CTR $+\mathrm{LY}, \mathrm{HI}$, and $\mathrm{HI}+\mathrm{LY}$ animals, respectively. During the experimental period (0-240 minutes), NHGO was not altered in either CTR or CTR+LY animals. On the other hand, infusion of insulin into the head even- 
A
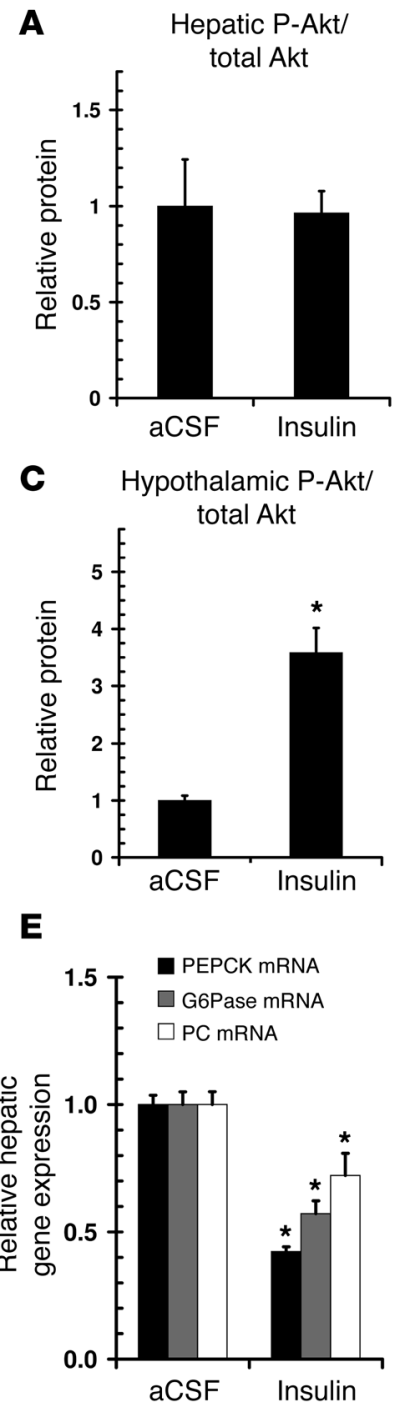
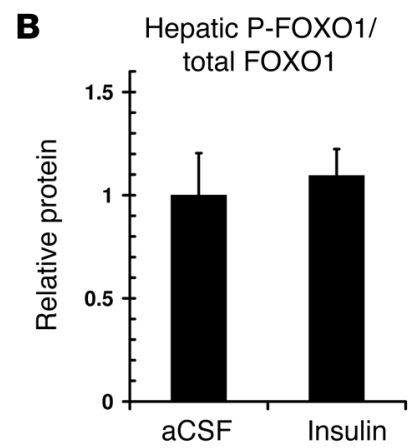

D

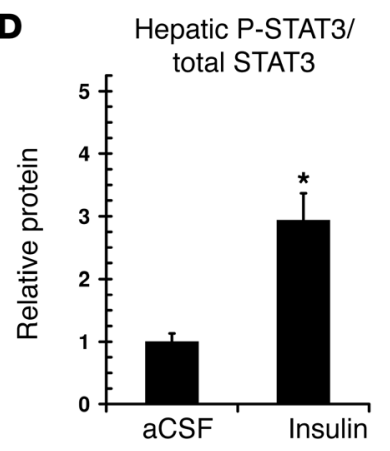

$\mathbf{F}$

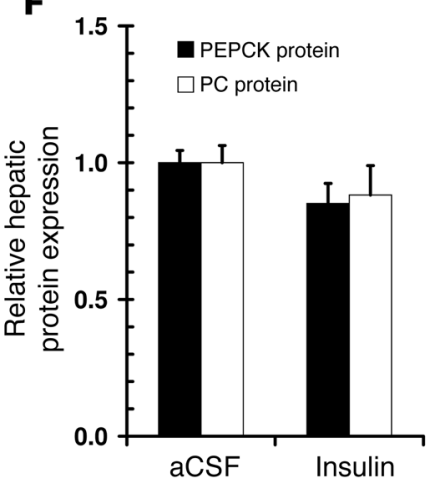

tually suppressed NHGO, so that during the last hour of the clamp, it was reduced by $0.62 \pm 0.27 \mathrm{mg} / \mathrm{kg} / \mathrm{min}(P<0.05$, HI vs. basal period and vs. all other groups; Figure $5 \mathrm{~B})$. The suppressive effect of elevated head insulin on NHGO was blocked by concurrent inhibition of brain PI3K in the HI+LY group. NHGNG flux was unaffected by head insulin infusion (Figure 5C), whereas NHGLY flux decreased by $0.63 \pm 0.21 \mathrm{mg} / \mathrm{kg} / \mathrm{min}(P<0.05$; Figure 5D). This decrease was also blocked by brain PI3K inhibition.

Tracer-derived EGP remained at near-basal levels in all groups for the duration of the experiment (Figure 6A). Whole-body glucose Rd and clearance also remained basal, while glucose infusion remained near 0, in CTR and CTR+LY animals (Figure 6, B-D). On the other hand, glucose Rd, clearance, and infusion rate all increased in the HI and $\mathrm{HI}+\mathrm{LY}$ groups as a result of the rise in arterial insulin. Wholebody gluconeogenesis and glycogenolysis were assessed using ${ }^{2} \mathrm{H}_{2} \mathrm{O}$; no changes were detected (Figure 6, E and F). Taken together, these data support the notion that brain insulin action can modestly suppress NHGO by enhancing hepatic glucose uptake and glycogen synthesis, but that it does not suppress HGP or gluconeogenesis.

At the molecular level, hepatic Akt and FOXO1 phosphorylation and hepatic gene expression of key gluconeogenic regulators (SRC1,

\section{Figure 3}

Effect of the i.c.v. insulin protocol on hepatic and hypothalamic insulin signaling and gluconeogenic enzyme expression. (A-F) Insulin did not alter hepatic phosphorylation of Akt (A) or FOXO1 (B), but did stimulate hypothalamic phosphorylation of Akt (C) and hepatic phosphorylation of STAT3 (D), resulting in decreases in gluconeogenic mRNA expression (E). (F) Insulin did not significantly alter gluconeogenic enzyme protein levels. Values are means \pm SEM. $n=5$. ${ }^{*} P<0.05$ vs. aCSF.

SRC2, PGC1 $\alpha$, and FOXO1) did not differ among groups (Figure 7, $\mathrm{A}$ and B, and Supplemental Figure 2). Hypothalamic phosphoAkt and hepatic phospho-STAT3 were not elevated in the CTR and CTR+LY groups, but increased 3- and 1.7-fold, respectively, in response to head insulin infusion (Figure $7, \mathrm{C}$ and $\mathrm{D}$ ). These increases were prevented by brain PI3K inhibition. Hepatic mRNA levels of PEPCK, G6Pase, and PC and hepatic protein levels of PEPCK and $\mathrm{PC}$ were decreased by elevated head insulin, and these decreases were prevented with concurrent i.c.v. LY infusion (Figure 7, E and F).

The effect of brain insulin action on NHGLY flux only became apparent after several hours, suggestive of genetic regulation. While head insulin had no discernable effect on glycogen synthase (GS) or glycogen phosphorylase (GP) mRNA expression, it increased glucokinase (GK) mRNA 3-fold, without increasing GK protein expression (Figure 8, A and B). On the other hand, hepatic GS kinase $3 \beta$ (GSK3 $\beta$ ) mRNA expression was decreased approximately $40 \%$ when head insulin was elevated. This correlated with a corresponding decrease in both GSK $3 \beta$ protein and GS phosphorylation (Figure 8, C and D). It must be noted that the level of phosphorylated GSK3 $\beta$ was not altered by head insulin (Figure $8 \mathrm{C}$ ), which suggests that the reduction of GSK3 $\beta$ 's ability to phosphorylate and inhibit GS was entirely a function of reduced nonphosphorylated GSK3 $\beta$ protein levels. Concurrent i.c.v. infusion of LY blocked the effects of head insulin on hepatic GSK3 $\beta$ protein and mRNA expression as well as GS phosphorylation.

Finally, we assessed the effect of brain hyperinsulinemia on hepatic glucose metabolism in dogs subjected to hepatic denervation 2 weeks prior to study (referred to herein as HI+DN; $n=4$ ). We assayed norepinephrine levels in terminal liver biopsies as an index of hepatic neural input. Relative to nondenervated animals, hepatic norepinephrine levels decreased $86 \%$ in HI+DN livers, indicative of substantial but incomplete removal of nerve input to the liver. Brain hyperinsulinemia ( 10-fold) in the $\mathrm{HI}+\mathrm{DN}$ group (with liver insulin, glucagon, and NEFA clamped at basal) resulted in increased hypothalamic Akt phosphorylation similar to that of the HI group (Supplemental Tables 5 and 6). However, 86\% hepatic denervation only partially blunted the ability of brain insulin to increase liver STAT3 phosphorylation and to suppress gluconeogenic gene expression, and failed to alter the effects on GSK3 $\beta$ protein and GS phosphorylation levels (Supplemental Table 6). As a result, the suppression of NHGO was similar between the HI and HI+DN groups (Supplemental Tables 5 and 6).

\section{Discussion}

We have shown, for the first time to our knowledge in a large animal model, that acute physiologic elevation of brain insulin (brought about in the presence of basal hepatic insulin and glucagon levels) can activate insulin signaling in the hypothalamus and mediate alterations in the liver, as evidenced by STAT3 phosphorylation and suppression of PEPCK and G6Pase mRNA expression. Furthermore, selective brain insulin action also altered the genetic 

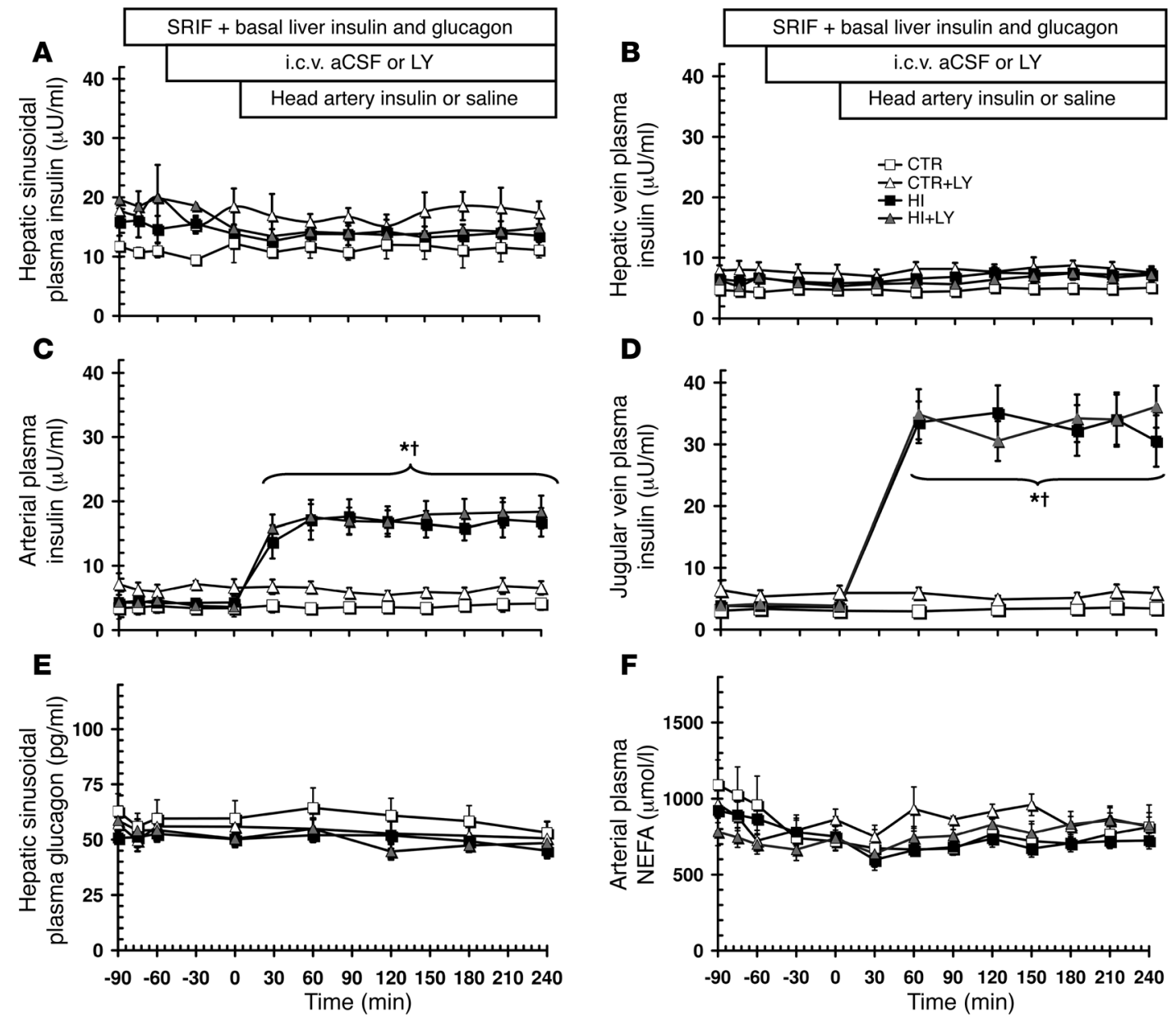

\section{Figure 4}

Plasma insulin, glucagon, and NEFA in dogs subjected to the head artery insulin infusion protocol. As illustrated above graphs, 42-hour fasted conscious dogs received peripheral infusion of somatostatin and were maintained on a pancreatic clamp at basal levels of hepatic insulin, glucagon, and NEFA, then exposed to saline or insulin infusion into head arteries with i.c.v. infusion of either vehicle or LY. (A) Hepatic sinusoidal plasma insulin. (B) Hepatic vein plasma insulin. (C) Arterial plasma insulin. (D) Jugular vein plasma insulin. (E) Hepatic sinusoidal plasma glucagon. (F) Arterial plasma NEFA levels. Values are mean \pm SEM. $n=4$ (CTR and CTR+LY); $8(\mathrm{HI}) ; 7(\mathrm{HI}+\mathrm{LY}) .{ }^{*} P<0.05, \mathrm{HI}$ and HI+LY vs. CTR and $\mathrm{CTR}+\mathrm{LY} ;{ }^{\dagger} P<0.05, \mathrm{HI}$ and $\mathrm{HI}+\mathrm{LY}$ vs. basal period.

regulation of $\mathrm{PC}, \mathrm{GK}$, and GSK3 $\beta$ in the liver, which we believe to be novel findings. The suppression of GSK3 $\beta$ mRNA was correlated with reductions in GSK3 $\beta$ protein levels and GS phosphorylation, which in turn were associated with decreased NHGO attributable to enhanced hepatic glycogen synthetic flux. All of these changes were prevented by the inhibition of hypothalamic insulin signaling. Infusion of insulin into head arteries, however, did not alter EGP or its gluconeogenic and glycogenolytic components, thus countering the perception that insulin signaling in the brain is responsible for acute inhibition of HGP.

Insulin infusion i.c.v. in dogs, at the same rate as previously demonstrated to regulate EGP in rats (5), activated Akt in the hypothalamus and brought about signaling changes in the liver, but did not significantly alter EGP, despite creating a level of CSF insulin far above what would ever exist in vivo. Although our i.c.v. studies confirmed that brain insulin action can regulate transcriptional events in the liver, the physiological relevance of insulin infusion via this route and at this dose remains unclear. Knowing that the insulinbrain-liver signaling axis was intact in dogs, we undertook a second set of experiments to determine whether a physiologic increase in brain insulin could activate central signaling and thereby modify hepatic glucose metabolism in vivo. To this end, we brought about an increase in brain insulin that was physiologic in both its route of administration (infused into the arteries that perfuse the brain) and its magnitude ( $\sim 10$-fold increase), the latter being within the physiologic range of arterial hyperinsulinemia seen after a mixed meal (26). In order to allow the impact of such a change to be clearly seen, we maintained basal insulin and glucagon levels at the liver. Head artery insulin infusion brought about a small but significant reduction in NHGO $(\sim 0.6 \mathrm{mg} / \mathrm{kg} / \mathrm{min} ; \sim 40 \%)$ that was entirely a function of a reduction in NHGLY flux $(\sim 0.6 \mathrm{mg} / \mathrm{kg} / \mathrm{min})$. That significant decreases in NHGO and NHGLY flux were observed, with no alterations of EGP, gluconeogenesis, or glycogenolysis, suggests that brain insulin stimulated hepatic GS flux and hepatic glucose uptake, since these factors are accounted for in the calculation of net hepatic balance but not in the measurement of tracerderived EGP. We cannot exclude a small effect of brain insulin on muscle glucose uptake, but this seems unlikely, given that brain 

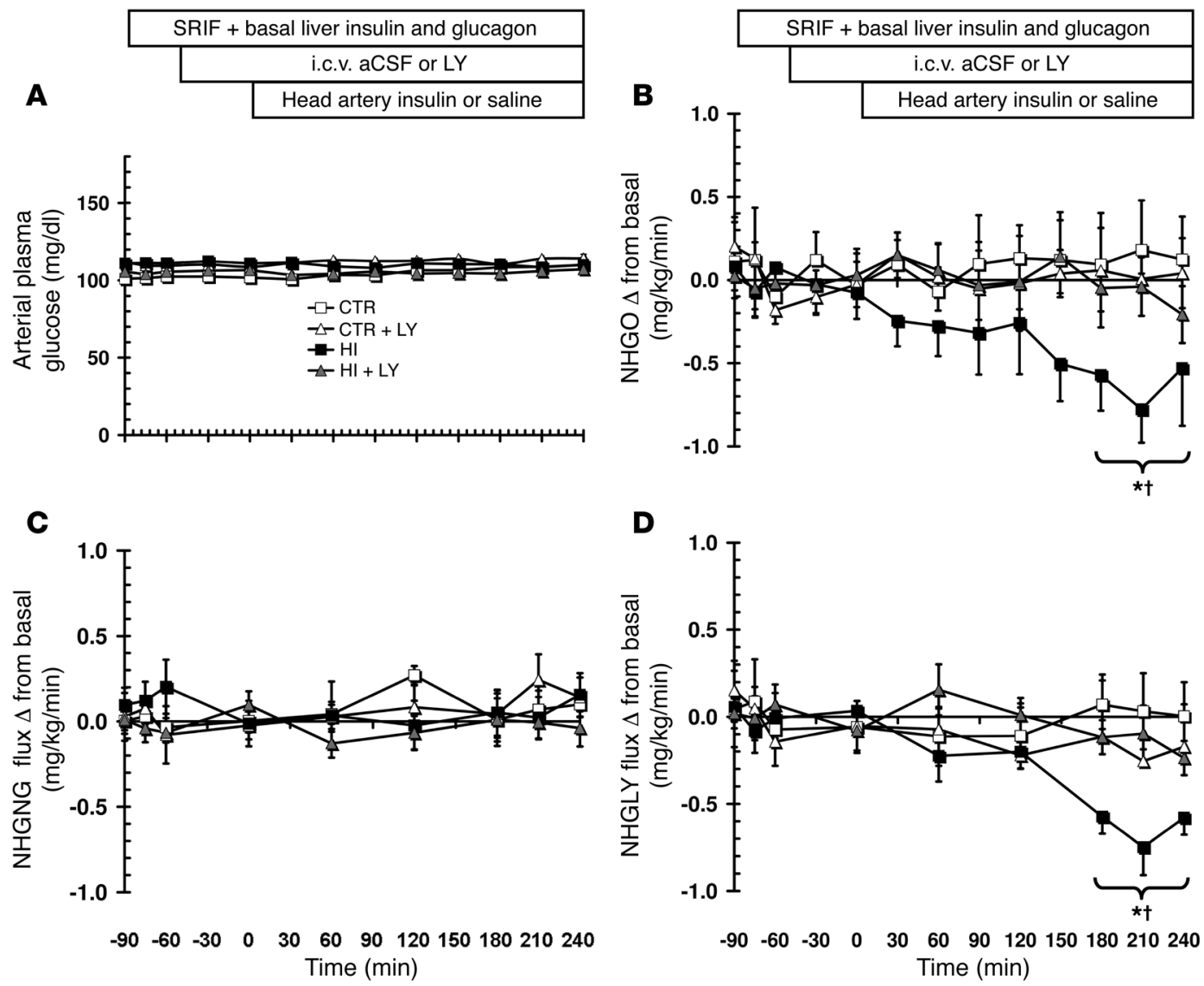

Figure 5

Effect of the head artery insulin infusion protocol on net hepatic glucose flux parameters. (A) Euglycemic conditions. (B) Suppression of NHGO in the $\mathrm{HI}$ group was blocked in the HI+LY group. (C) NHGNG flux was unaltered by head insulin. Basal NHGNG flux rates: CTR, $0.57 \pm 0.01 \mathrm{mg} / \mathrm{kg} / \mathrm{min}$; CTR+LY, $0.85 \pm 0.07 \mathrm{mg} / \mathrm{kg} / \mathrm{min} ; \mathrm{HI}, 0.98 \pm 0.10 \mathrm{mg} / \mathrm{kg} / \mathrm{min} ; \mathrm{HI}+\mathrm{LY}, 0.91 \pm 0.04 \mathrm{mg} / \mathrm{kg} / \mathrm{min}$. (D) The decrease in NHGO in the HI group was entirely a result of decreased NHGLY flux. Basal NHGLY flux rates: CTR, $0.56 \pm 0.12 \mathrm{mg} / \mathrm{kg} / \mathrm{min} ; \mathrm{CTR}+\mathrm{LY}, 0.86 \pm 0.08 \mathrm{mg} / \mathrm{kg} / \mathrm{min} ; \mathrm{HI}, 0.82 \pm$ $0.15 \mathrm{mg} / \mathrm{kg} / \mathrm{min} ; \mathrm{HI}+\mathrm{LY}, 0.51 \pm 0.06 \mathrm{mg} / \mathrm{kg} / \mathrm{min}$. Values are mean $\pm \mathrm{SEM} . n=4$ (CTR and CTR $+\mathrm{LY}) ; 8(\mathrm{HI}) ; 7(\mathrm{HI}+\mathrm{LY}) .{ }^{*} P<0.05, \mathrm{HI}$ vs. all other groups; ${ }^{\dagger} P<0.05$ vs. basal period.

insulin action tended to increase glucose infusion rate and wholebody glucose $\mathrm{Rd}$ to the same extent as the increase in net hepatic glucose uptake $(\sim 0.6 \mathrm{mg} / \mathrm{kg} / \mathrm{min})$. These 3 independent measurements were consistent with the notion that brain insulin action specifically stimulates glucose uptake by the liver.

The question arises as to why head artery insulin infusion brought about a larger decrease in NHGO than did i.c.v. insulin infusion, despite a much larger increase in CSF insulin with i.c.v. infusion. We speculate that i.c.v.-delivered insulin did not access all the CNS nuclei relevant to glucose homeostasis in a manner that reproduced physiologic insulinization via head artery insulin infusion. It is also possible that extended fasting conditions (dogs in the head artery infusion protocol were fasted 42 hours) were permissive to the small effect brain insulin has on liver glycogen metabolism in our model. In any case, our results highlight that responses to i.c.v. infusion of compounds must be evaluated with caution and emphasize the advantage of the technically challenging, but physiologically relevant, method of infusing hormones into the head arteries.

We next investigated the mechanism by which brain hyperinsulinemia stimulated hepatic glucose uptake and glycogen synthetic flux. Hepatic GS and GP are rapidly regulated in a reciprocal and coordinated fashion in response to a rise in plasma insulin or glucose in vivo (27). In contrast, the slow time course of brain insulin action on NHGLY flux observed in the present study suggests that the process is regulated at the transcriptional level. STAT3 has been proposed to be the hepatic effector of the insulin-brain-liver effect (9) on gluconeogenic gene expression, but STAT3 phosphorylation can also inhibit GSK3 $\beta$ gene expression (28). Indeed, brain hyperinsulinemia was associated with decreases in hepatic GSK3 $\beta$ mRNA and protein expression and a corresponding decrease in GS phosphorylation. Thus, we propose that selective, physiological hyperinsulinemia in the arterial blood supply to the brain can bring about STAT3 phosphorylation in the liver, resulting in suppression of hepatic GSK3 $\beta$ mRNA expression and eventually leading to a fall in GSK3 $\beta$ protein levels, thus relieving GS from GSK3 $\beta$-mediated inhibition.

It should be noted that our experimental design, in which hepatic insulin, glucagon, and NEFA were clamped at basal values, would have excluded CNS insulin from mediating whole-body glucose metabolism through its established effects on pancreatic insulin or glucagon secretion (2-4) or on adipose tissue lipolysis (29). In addition, the insulin-brain-liver effect on NHGO reported in the present study does not recapitulate the suppression of NHGO by physi- 


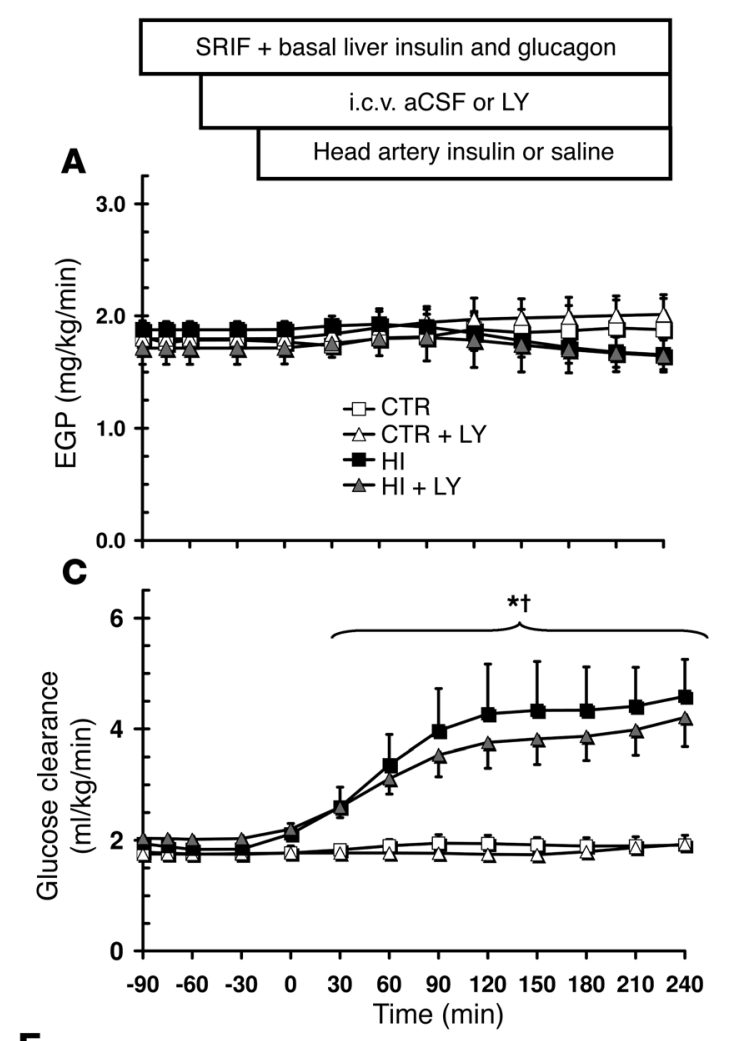

$\mathbf{E}$

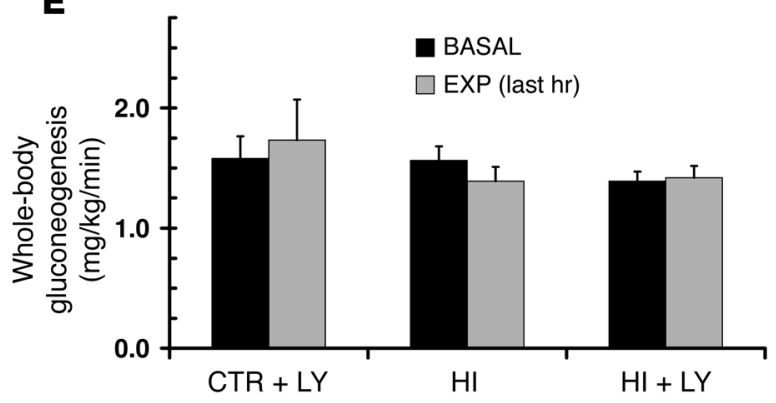

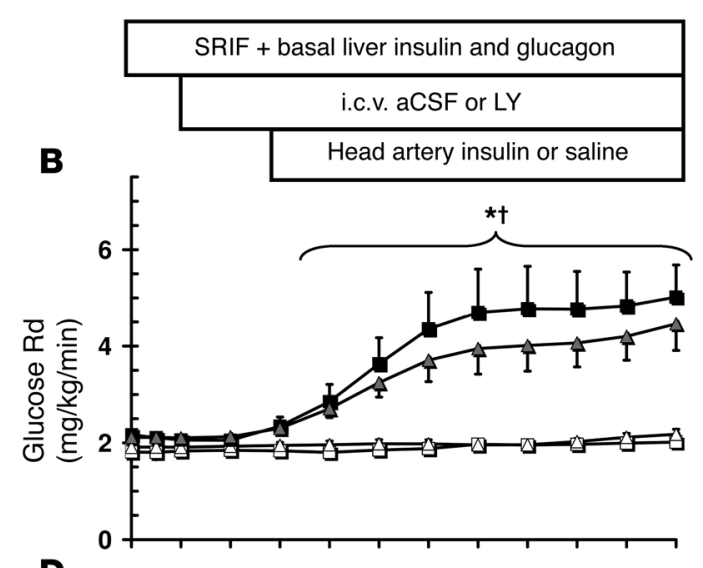

D

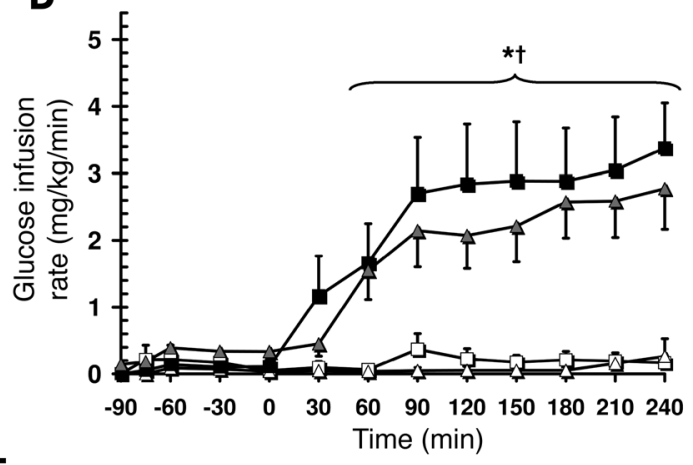

$\mathbf{F}$

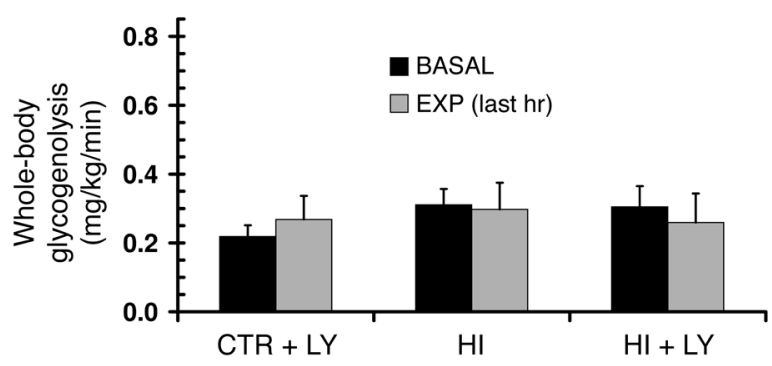

Figure 6

Effect of the head artery insulin infusion protocol on tracer-derived glucose flux parameters. (A) EGP. (B) Glucose Rd. (C) Glucose clearance. (D) Glucose infusion rate. (E) Whole-body gluconeogenesis. (F) Whole-body glycogenolysis. Values are mean \pm SEM. (A-D) $n=4$ (CTR and CTR+LY); 8 (HI); 7 (HI+LY). (E and F) $n=3$ (CTR+LY); 4 (CTR, HI, and HI+LY). ${ }^{*} P<0.05, \mathrm{HI}$ and HI+LY vs. CTR and CTR+LY; ${ }^{\dagger} P<0.05, \mathrm{HI}$ and $\mathrm{HI}+\mathrm{LY}$ vs. basal period.

ological hyperinsulinemia in several regards. First, meal-associated hyperinsulinemia is transient, peaking within 1 hour and subsiding within 2-3 hours (1). Second, brain hyperinsulinemia is always accompanied by hepatic hyperinsulinemia, so that the liver is subject to insulin's established rapid (19) and dominant (20) direct effects on NHGO. Third, systemic hyperinsulinemia potently suppresses lipolysis, and the consequent fall in circulating NEFAs (which was prevented in this study with Intralipid plus heparin infusion) plays a key role in regulating $\mathrm{NHGO}(19,22-25)$. In fact, the suppression of NHGO brought about by selective peripheral hyperinsulinemia (i.e., in the presence of basal hepatic insulin) was largely negated in dogs when circulating NEFAs were maintained at basal with Intralipid plus heparin infusion (24). Fourth, NHGO is completely suppressed within 1 hour in response to an acute, approximately 8-fold increase in portal insulin secretion (25). Therefore, the effect of brain insulin action on the liver ( $\sim 40 \%$ decrease in NHGO after 3-4 hours) may not be relevant to the acute suppression of NHGO observed in previous euglycemic insulin clamp studies $(19,22-25)$, although this remains to be directly evaluated.

It may be that the relevance of insulin's effect on the brain becomes magnified during the response to a meal when there is hyperglycemia and a drive for liver glucose uptake. The effect of the portal glucose signal, which is neurally driven and which markedly stimulates hepatic glucose uptake during feeding (1), may be enhanced by insulin's effects in the CNS. In addition, although brain insulin action did not have an acute impact on EGP in the present study, longer-term alteration in brain insulin signaling (i.e., hypothalamic insulin resistance) could further alter functional protein levels of PEPCK, G6Pase, PC, GK, and GSK3 $\beta$ and thereby modify HGP and/or further alter hepatic glucose uptake. 
A
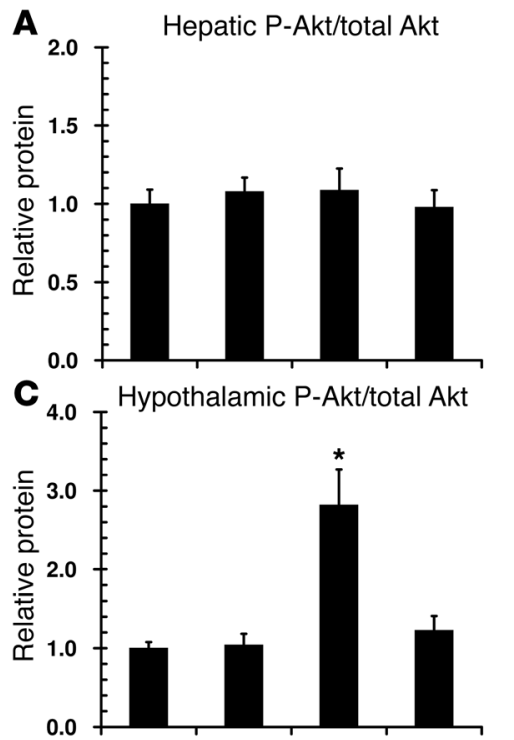

$\mathbf{E}$

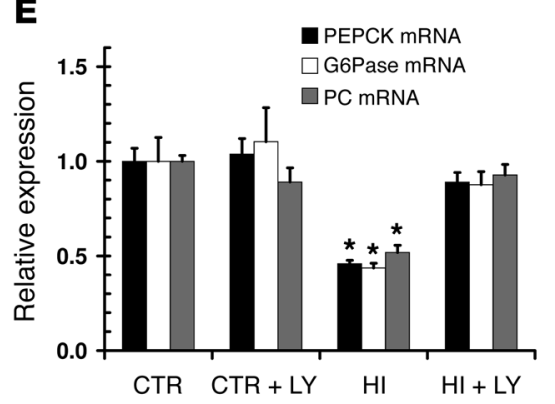

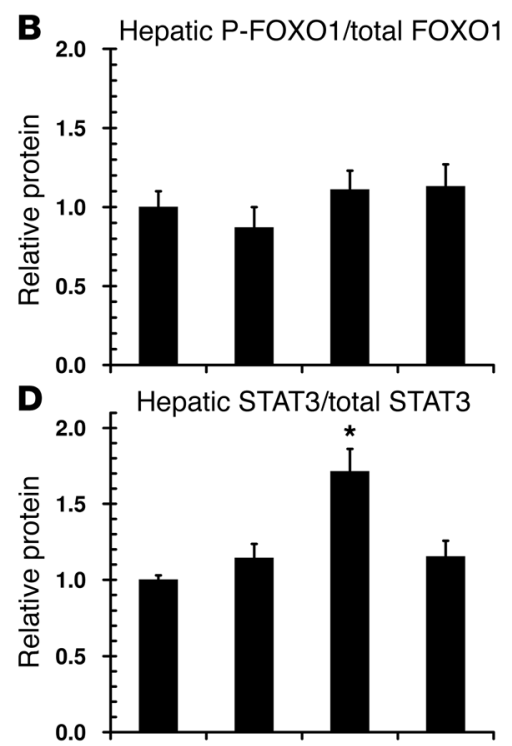

$\mathbf{F}$

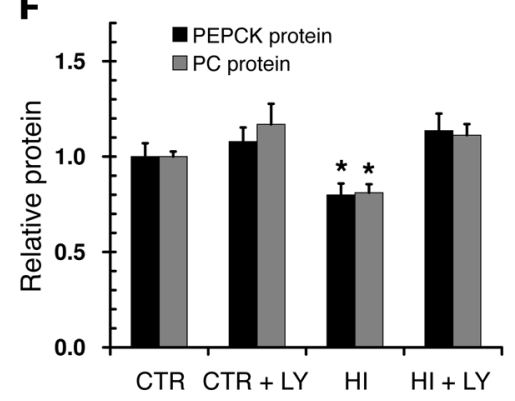

Figure 7

Effect of the head artery insulin infusion protocol on cellular indices relevant to gluconeogenesis. (A and B) Phosphorylation of liver Akt (A) and liver FOXO1 (B) were not different between groups. (C-F) The HI group demonstrated increased phosphorylation of hypothalamic Akt (C), increased phosphorylation of hepatic STAT3 (D), decreased PEPCK, G6Pase, and PC mRNA expression (E), and decreased levels of PEPCK and PC protein $(\mathbf{F})$; these effects were all blunted in the HI+LY group. Values are means $\pm S E M$. $n=4(\mathrm{CTR}$ and $\mathrm{CTR}+\mathrm{LY}) ; 8(\mathrm{HI}) ; 7(\mathrm{HI}+\mathrm{LY}) .{ }^{*} P<0.05$ vs. all other groups.

It is not surprising that gluconeogenic gene expression was markedly suppressed by brain insulin action without altering flux through the pathway. STAT3 phosphorylation requires several hours to occur in response to hyperinsulinemic clamps in mice and dogs $(9,25)$. It then takes several more hours for STAT3-driven alterations in gene expression to result in changes in protein levels (25); thus, the changes in gluconeogenic enzyme levels were small. Furthermore, the subtle decrease in gluconeogenic enzyme levels observed in the present study would not be expected to alter gluconeogenic flux, given that physiological increases in portal vein insulin infusion can reduce PEPCK protein up to $50 \%$ in dogs without altering the gluconeogenic rate (25). The question then arises as to how brain insulin-mediated decreases in gluconeogenic gene expression could have caused a functional reduction in gluconeogenesis in the rodent. It is possible that there are species differences in protein turnover of gluconeogenic enzymes, but even substantial reductions of PEPCK in rodent liver have minimal effect on the gluconeogenic pathway (30). It is also possible that the sensitivity of gluconeogenesis to brain insulin signaling is species dependent. Rodents have basal EGP rates 5-10 times higher than those in dogs or humans per unit of body weight (31). Furthermore, rodents almost completely deplete liver glycogen stores after a relatively short fast (32), whereas the 42-hour fasted dog retains approximately $25 \%$ of its peak prandial hepatic glycogen level (33). Thus, glycogenolysis (assessed using ${ }^{2} \mathrm{H}_{2} \mathrm{O}$ infusion) accounted for approximately $15 \%$ of basal EGP after 42 hours of fasting in the current study, in agreement with the percent contribution of glycogenolysis to EGP in humans after a similarly extended fast (34). The contribution of the gluconeogenic pathway to glucose production is therefore absolutely and proportionally higher in rodents than in large animals, thereby making changes in the gluconeogenic rate more likely to occur and more easily detected.

It is also possible that brain insulin-mediated suppression of gluconeogenesis occurred in the rodent studies, and not the present study, because of the differences in hepatic sinusoidal insulin and glucagon concentrations that resulted from differences in experimental design. Peripheral replacement of insulin in the rodent (5) would have eliminated the naturally occurring insulin gradient between the liver and peripheral tissues and would have amplified the importance of insulin's central action relative to what would occur in normal physiology. In addition, glucagon was not replaced in the rodent studies $(5-11,13)$, despite somatostatin's established, potent inhibitory effect on glucagon secretion in rodents (35). Since glucagon is the most significant factor in the stimulation of basal HGP (largely by promoting glycogenolysis) after fasting in humans, dogs, and rodents (36-38), its absence would therefore acutely increase the relative importance of gluconeogenesis, even though it may have tended to decrease gluconeogenic gene transcription. Glucagonopenia may have therefore been permissive for the observed brain insulin action on the gluconeogenic rate in rodents.

Brain insulin action in the rodent is sensitive to selective hepatic efferent vagotomy, a procedure that we could not reproduce in the dog. Instead, we attempted to determine the importance of intact neural input to the insulin-brain-liver signaling axis by performing head artery insulin infusion clamps in dogs that were previously subjected to nonselective hepatic denervation (i.e., parasympathetic/sympathetic/nonadrenergic noncholinergic fibers as well as afferent/efferent fibers). Liver norepinephrine levels indicated that hepatic denervation resulted in substantial, yet incomplete, removal of hepatic neural input (an 86\% decrease). Predictably, incomplete liver denervation only partially blunted the effects of brain insulin on hepatic STAT3 phosphorylation and gluconeogenic gene expression. Denervation did not prevent suppression of NHGO, however, consistent with a failure to reduce hepatic GSK $3 \beta$ protein expression or GS phosphorylation. It may be that the residual nerve input was sufficient to mediate some aspects of insulin-brain-liver signaling. It is also possible that the insulin-brain-liver signaling axis may be partially independent of intact hepatic nerves, instead occurring secondary to neural signaling to extrahepatic tissues. In addition, a chronically denervated liver may be subject to adaptations that 
A

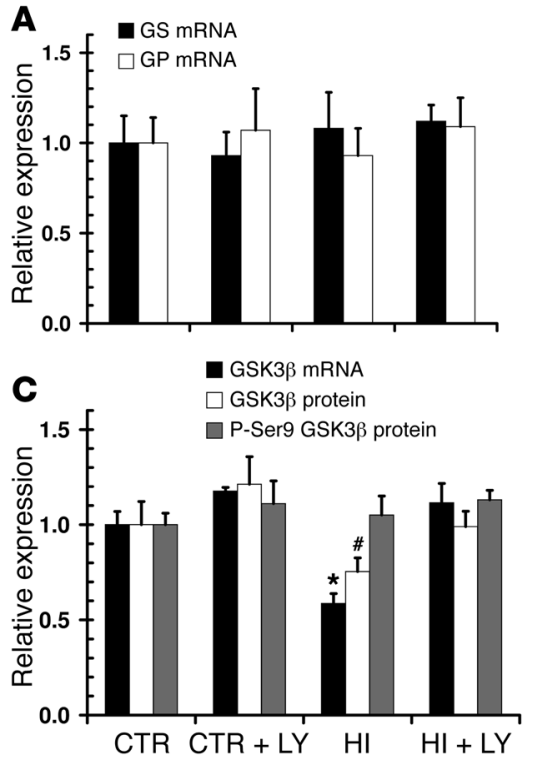

B

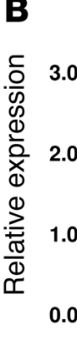

D

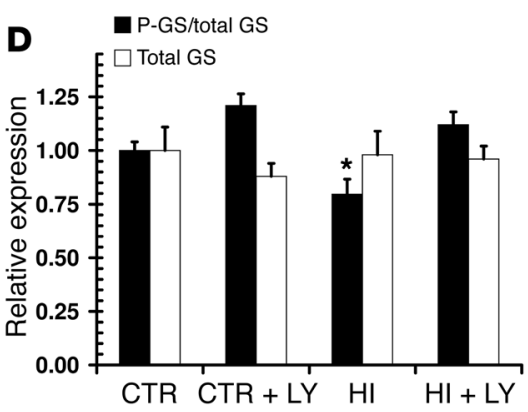

\section{Figure 8}

Effect of the head artery insulin infusion protocol on markers of glucose uptake and glycogen metabolism. (A and B) Selective head hyperinsulinemia did not regulate GS or GP mRNA $(\mathbf{A})$ and increased GK mRNA expression, but did not alter GK protein levels (B). (C and D) GSK3 $\beta$ protein and mRNA expression were both reduced in $\mathrm{HI}$ animals $(\mathbf{C})$, and there was a corresponding suppression of GS phosphorylation (D); these effects were blocked in the $\mathrm{HI}+\mathrm{LY}$ group. Values are mean \pm SEM. $n=4$ (CTR and CTR+LY); $8(\mathrm{HI}) ; 7(\mathrm{HI}+\mathrm{LY}) .{ }^{\star} P<0.05$ vs. all other groups; ${ }^{*} P<0.05$ vs. CTR and CTR+LY. alter its sensitivity to the brain insulin effect. Thus, although these denervation studies provide further evidence that insulin acting in the brain can affect hepatic glucose metabolism, subsequent studies will be required to clarify the route(s) by which the liver is signaled.

In summary, we demonstrated that the brains of dogs can sense physiologic increases in plasma insulin that, in turn, regulate signaling events in the liver (STAT3 phosphorylation and the genetic regulation of gluconeogenesis and glycogen metabolism). Even though the hepatic sinusoidal levels of insulin, glucagon, and NEFA were clamped at basal values, a 10 -fold increase in brain insulin (brought about by infusion of the hormone into head arteries) only modestly inhibited NHGO and took several hours to do so. There was no effect on tracer-determined EGP, which suggests that brain insulin action brought about its effect by stimulating hepatic glucose uptake rather than by suppressing output. This, in turn, was attributable to an increase in glycogen synthetic flux, secondary to a suppression of GSK $3 \beta$ mRNA and protein expression and a consequent reduction in GS phosphorylation. We conclude that although the canine brain can sense physiologic elevations in insulin and regulate transcriptional events in the liver, this input does not acutely regulate HGP, gluconeogenesis, or glycogenolysis. Selectively increasing insulin in the brain can, however, augment hepatic glucose uptake and glycogen synthetic flux within a 4-hour period. Our present findings point to the need for future evaluation of the relevance of brain insulin action to hepatic glucose uptake and storage in the context of hepatic hyperinsulinemia and hyperglycemia in normal animals and in models of insulin resistance.

\section{Methods}

Animal care and surgical procedures. Experiments were performed on either 18-hour (i.c.v. protocol) or 42-hour (head artery protocol) fasted, conscious mongrel dogs of either sex $(18-25 \mathrm{~kg})$. The surgical facility met the standards published by the American Association for the Accreditation of Laboratory Animal Care guidelines, and the protocol was approved by the Vanderbilt University Medical Center Animal Care Committee.

At 2 weeks prior to study, a laparotomy was performed for catheterization of the jejunal and splenic veins (for intraportal infusion), the femoral artery, the hepatic portal vein, and the hepatic vein (for sampling) and for placement of ultrasonic flow probes (Transonic Systems) around the hepatic artery and portal vein, as previously described (25). In a subset of studies, hepatic denervation was performed at this time, as described previously (18). At 1 week prior to study, additional infusion catheters were placed bilaterally in the carotid and vertebral arteries, a sampling catheter was inserted in the internal jugular vein, and i.c.v. cannulation was performed stereotaxically. Proper placement of the cannula into the third ventricle was confirmed by observation of CSF reflux upon removal of the stylet, both on the day of surgery and on the day of the experiment, and also confirmed by postmortem examination of the location of the cannula tip in the brain. All the animals studied met the established criteria for good health: (a) leukocyte count less than $16,000 / \mathrm{mm}^{3}$, (b) hematocrit greater than $35 \%$, (c) good appetite, and (d) normal stools. On the day of the study, catheters were placed in leg veins for peripheral infusion of $\left[3-{ }^{3} \mathrm{H}\right]$ glucose (Du Pont NEN), somatostatin (Bachem), glucose (20\% dextrose; Baxter Healthcare), and Intralipid (Abbott) plus heparin (head artery insulin infusion protocol only).

Experimental design. The i.c.v. insulin experiment consisted of equilibration ( -120 to -30 minutes), basal ( -30 to 0 minutes), and experimental ( 0 to 240 minutes) periods. At -120 minutes, a priming dose of $\left[3-{ }^{3} \mathrm{H}\right]$ glucose $(35 \mu \mathrm{Ci})$ was given, followed by a constant $(0.35 \mu \mathrm{Ci} / \mathrm{min})\left[3-{ }^{3} \mathrm{H}\right]$ glucose infusion. At -120 minutes, a pancreatic clamp was initiated with peripheral somatostatin infusion $(0.8 \mu \mathrm{g} / \mathrm{kg} / \mathrm{min})$, and portal infusion of glucagon at a basal rate $(0.57 \mathrm{ng} / \mathrm{kg} / \mathrm{min}$; Lilly). Insulin (Lilly) infusion was matched to the animal's endogenous level of secretion by adjusting the intraportal insulin infusion rate as necessary to maintain glucose at basal levels. The last change in insulin infusion rate was made at least 30 minutes before the start of the basal period. At 0 minutes, i.c.v. infusion of either aCSF $(0.01 \mathrm{ml} / \mathrm{min} ; n=5)$ or insulin in aCSF $(0.42 \mu \mathrm{U} / \mathrm{kg} / \mathrm{min} ; 0.01 \mathrm{ml} / \mathrm{min} ; n=5)$ was initiated. CSF is known to enter the systemic circulation at $50 \mu \mathrm{l} / \mathrm{min}$ in the $\mathrm{dog}$ (39); thus, leakage of CSF insulin $(\sim 70 \mu \mathrm{U} / \mathrm{ml})$ into systemic circulation would equate to less than $0.2 \mu \mathrm{U} / \mathrm{kg} / \mathrm{min}$, a minute and insignificant amount compared with the basal portal vein infusion rate $(196 \pm 33$ and $198 \pm 12 \mu \mathrm{U} / \mathrm{kg} / \mathrm{min}$ in the aCSF and insulin plus aCSF groups, respectively).

In the head artery protocol, 4 groups of animals were studied: saline plus i.c.v. aCSF (CTR; $n=4)$, saline plus i.c.v. LY $(\mathrm{CTR}+\mathrm{LY} ; n=4)$, selective head hyperinsulinemia plus i.c.v. aCSF (HI; $n=8)$ and selective head hyperinsulinemia plus i.c.v. LY $(\mathrm{HI}+\mathrm{LY} ; n=7)$. Each experiment consisted of an equili- 
bration (-180 to -90 minutes), basal ( -90 to 0 minutes), and experimental ( 0 to 240 minutes) period. At -180 minutes, salinized ${ }^{2} \mathrm{H}_{2} \mathrm{O}$ ( $3 \mathrm{ml} / \mathrm{kg}$; SigmaAldrich) was administered i.v. as described previously (25). At -180 minutes, a priming dose of $\left[3-{ }^{3} \mathrm{H}\right]$ glucose $(35 \mu \mathrm{Ci})$ was given, followed by a constant infusion $(0.35 \mu \mathrm{Ci} / \mathrm{min})$ of $\left[3-{ }^{3} \mathrm{H}\right]$ glucose infusion. At the same time, a pancreatic clamp was initiated (peripheral somatostatin infusion and portal replacement of basal glucagon and basal insulin matched to animal's endogenous level of secretion) as in the i.c.v. protocol. Basal insulin infusion rates were as follows: CTR, $229 \pm 49 \mu \mathrm{U} / \mathrm{kg} / \mathrm{min}$; CTR $+\mathrm{LY}$, $248 \pm 27 \mu \mathrm{U} / \mathrm{kg} / \mathrm{min} ; \mathrm{HI}, 233 \pm 26 \mu \mathrm{U} / \mathrm{kg} / \mathrm{min} ; \mathrm{HI}+\mathrm{LY}, 226 \pm 25 \mu \mathrm{U} / \mathrm{kg} / \mathrm{min}$. After the basal sampling period (-90 to -60 minutes), either aCSF or LY was infused into the i.c.v. cannula (-60 to 240 minutes). At 0 minutes, saline was infused bilaterally into the carotid and vertebral arteries (CTR, CTR $+\mathrm{LY})$, or the intraportal insulin infusion was stopped, and insulin was infused into the head arteries at a rate of $392 \pm 46 \mu \mathrm{U} / \mathrm{kg} / \mathrm{min}$ (HI, HI+LY) so as to bring about the maximal brain insulin level possible while maintaining basal insulin levels at the liver. Because this infusion rate also caused mild peripheral hyperinsulinemia and consequent inhibition of lipolysis, Intralipid and heparin were infused into a peripheral vein as described previously (24) beginning at 0 minutes to prevent a fall in circulating NEFA. Finally, peripheral glucose was infused as required to maintain euglycemia. Our goal was to fix the basal conditions at the liver so as to allow any input of brain insulin action on the liver to be manifest.

Immediately after obtaining the final blood sample, each animal (in both sets of experiments) was anesthetized; with the various infusions still ongoing, a laparotomy was rapidly performed so that sections of liver could be freeze-clamped and subsequently stored at $-70^{\circ} \mathrm{C}$. Molecular analyses depict the average of findings in the 3 largest liver lobes. Immediately thereafter, each animal was euthanized, CSF was sampled from the cisterna magna, and the cranial vault was opened with a bone saw. The brain was removed, and from its ventral aspect, hypothalamic tissue was excised from an area extending between the optic chiasm and the mamillary bodies, $5 \mathrm{~mm}$ to either side of the infundibulum and to a depth of $10 \mathrm{~mm}$. The excised tissue was immediately freeze-clamped and stored at $-70^{\circ} \mathrm{C}$. In a separate experiment, the dissected tissue was sectioned and stained with hematoxylin and eosin. Using light microscopy, the neuroanatomic structure was evaluated to confirm the presence of hypothalamic tissue using the fornix column and the tuber cinereum as anatomical landmarks.

NMR $\left({ }^{2} \mathrm{H}\right)$ spectroscopy. Whole-body gluconeogenesis and glycogenolysis were calculated using the combined ${ }^{2} \mathrm{H}_{2} \mathrm{O}$ analysis-NMR detection method of Burgess et al. (40) that has been previously adapted in our lab (25). NMR spectra were generated independently for each animal.

Protein extraction and Western blotting. Soluble protein extracts were prepared from frozen canine liver and hypothalamus, and samples were subjected to Western blotting as previously described (25). Antibodies were supplied by Cell Signaling, with the exception of sheep anti-PEPCK (gift from D.K. Granner, Vanderbilt University Medical Center, Nashville, Tennessee, USA) and donkey anti-sheep secondary antibody (Sigma-Aldrich).

Real-time PCR. Total RNA was extracted by homogenizing frozen canine liver in Tri reagent (Sigma-Aldrich) following the manufacturer's instructions. First-strand cDNA was synthesized from total RNA using the High Capacity reverse transcription kit (Applied Biosystems). Real-time PCR conditions are described elsewhere (25); see Supplemental Table 7 for primers.

Analytical procedures. Hematocrit, plasma glucose, glucagon, insulin, cortisol, epinephrine, norepinephrine, and NEFA levels as well as blood alanine, glycine, serine, threonine, lactate, glutamine, glutamate, glycerol, and $\beta$-hydroxybutyrate concentrations were determined using standard procedures as previously described (25). We also assessed hepatic tissue norepinephrine in several control dogs and all 7 lobes of each hepatic denervated $\operatorname{dog}(n=4)$ to assess the extent of denervation as previously described (18).
General calculations. Net hepatic substrate balances (NHBs) were calculated with the A-V difference method as load out $_{-}-$load $_{i n}$, in which load $_{\text {out }}$ represents $[H] \times H F$ and load $_{\text {in }}$ represents $([A] \times A F)+([P] \times P F) ;[A],[P]$, and $[H]$ denote substrate concentrations in femoral artery, portal vein, and hepatic vein blood or plasma, respectively, and $A F, P F$, and $H F$ denote hepatic artery, portal vein, and total hepatic vein blood or plasma, respectively. With this calculation, positive values reflect net hepatic production and negative values represent net hepatic uptake. Plasma glucose values were converted to blood glucose values as previously described (25). Hepatic sinusoidal hormone concentrations were calculated as $([A] \times \% A F)+([P] \times \% P F)$, where $[A]$ and $[P]$ represent arterial and portal vein concentrations, respectively, and $\% A F$ and $\% P F$ are the respective fractional contributions of arterial and portal blood flow to total hepatic blood flow.

Gluconeogenic flux to G6P was determined by taking the sum of net hepatic uptake rates of gluconeogenic precursors (gluconeogenic amino acids, glycerol, lactate, and pyruvate) and dividing by 2 to account for the incorporation of 23 -carbon precursors into 16 -carbon glucose molecule. Net hepatic gluconeogenic (NHGNG) flux was estimated by subtracting glycolytic flux from total gluconeogenic flux to G6P. Glycolytic flux was estimated by taking the sum of the net hepatic output rates (when present) of the gluconeogenic substrates noted above (in glucose equivalents) and hepatic glucose oxidation (GO; assumed to be $0.2 \pm 0.1 \mathrm{mg} / \mathrm{kg} / \mathrm{min}$ ). We have previously verified that GO remains at this low rate across wide variations in physiological parameters (1). NHGLY flux was estimated by subtracting NHGNG flux from net hepatic glucose balance. Positive NHGLY flux reflects net glycogen breakdown, and negative values represent net glycogen synthesis.

There are several assumptions required when using the A-V difference technique in assessment of gluconeogenic flux to G6P, as discussed in detail previously (25). It must be noted that errors arising from the assumptions appear to be minimal, as simultaneous assessment of gluconeogenic flux using the $\mathrm{A}-\mathrm{V}$ difference technique and other independent methods (not subject to the same assumptions) yielded similar estimates of gluconeogenic flux (25).

We also determined whole-body gluconeogenesis and glycogenolysis using the ${ }^{2} \mathrm{H}_{2} \mathrm{O}$ method. Gluconeogenesis was calculated as the product of tracer-determined EGP, determined as previously described (41), and the ratio of deuterium enrichment at the respective carbon positions (C5/C2). Glycogenolysis was calculated as the value determined for gluconeogenesis subtracted from the EGP value.

Statistics. Metabolic data were analyzed using 2-way repeated-measures ANOVA (group $\times$ time) (SigmaStat). Molecular data were analyzed using 1-way ANOVA. A $P$ value less than 0.05 was considered significant.

\section{Acknowledgments}

This research was supported in part by NIH grant R01-DK-18243 and Diabetes Research and Training Center grant SP-60-AM20593. C.J. Ramnanan was supported by the American Diabetes Association Mentor-based Fellowship. A.D. Cherrington was supported by the Jacquelyn A. Turner and Dr. Dorothy J. Turner Chair in Diabetes Research. The authors thank Masakazu Shiota, Jon Hastings, Angelina Penaloza, Wanda Snead, Suzan Vaughan, and Kelli Boyd (Vanderbilt University School of Medicine) for their support.

Received for publication October 19, 2010, and accepted in revised form June 22, 2011.

Address correspondence to: Christopher J. Ramnanan, Molecular Physiology and Biophysics, Vanderbilt University School of Medicine, Nashville, Tennessee 37232-0615, USA. Phone: 615.322.7014; Fax: 615.343.0490; E-mail: chris.ramnanan@vanderbilt.edu. 
1. Cherrington AD. Banting Lecture 1997. Control of glucose uptake and release by the liver in vivo. Diabetes. 1999;48(5):1198-1214.

2. Woods SC, Porte D Jr. Neural control of the endocrine pancreas. Physiol Rev. 1974;54(3):596-619.

3. Chen M, Woods SC, Porte D Jr. Effect of cerebral intraventricular insulin on pancreatic insulin secretion in the dog. Diabetes. 1975;24(10):910-914.

4. Paranjape SA, et al. Influence of insulin in the ventromedial hypothalamus on pancreatic glucagon secretion in vivo. Diabetes. 2010;59(6):1521-1527.

5. Obici S, Zhang BB, Karkanias G, Rossetti L. Hypothalamic insulin signaling is required for inhibition of glucose production. Nat Med. 2002; 8(12):1376-1382

6. Lam TK, et al. Hypothalamic sensing of circulating fatty acids is required for glucose homeostasis. Nat Med. 2005;11(3):320-327.

7. Pocai A, Obici S, Schwartz GJ, Rossetti L. A brainliver circuit regulates glucose homeostasis. Cell Metab. 2005;1(1):53-61.

8. German J, et al. Hypothalamic leptin signaling regulates hepatic insulin sensitivity via a neurocircuit involving the vagus nerve. Endocrinology. 2009;150(10):4502-4511.

9. Inoue $\mathrm{H}$, et al. Role of hepatic STAT3 in braininsulin action on hepatic glucose production. Cell Metab. 2006;3(4):267-275.

10. Lam TK, Gutierrez-Juarez R, Pocai A, Rossetti L. Regulation of blood glucose by hypothalamic pyruvate metabolism. Science. 2005;309(5736):943-947.

11. Okamoto H, Obici S, Accili D, Rossetti L. Restoration of liver insulin signaling in Insr knockout mice fails to normalize hepatic insulin action. J Clin Invest. 2005;115(5):1314-1322.

12. Pocai A, et al. Hypothalamic K(ATP) channels control hepatic glucose production. Nature. 2005; 434(7036): 1026-1031.

13. Konner AC, et al. Insulin action in AgRP-expressing neurons is required for suppression of hepatic glucose production. Cell Metab. 2007;5(6):438-449.

14. Sandoval DA, Obici S, Seeley RJ. Targeting the CNS to treat type 2 diabetes. Nat Rev Drug Discov. 2009; 8(5):386-398.

15. Ono $H$. The hypothalamus bridges the gap between physiology and biochemistry in high-fat diet-induced hepatic insulin resistance. Cell Cycle. 2009;8(18):2885-2887.

16. Park S, Hong SM, Ahn IS. Long-term intracerebroventricular infusion of insulin, but not glu- cose, modulates body weight and hepatic insulin sensitivity by modifying the hypothalamic insulin signaling pathway in type 2 diabetic rats. Neuroendocrinology. 2009;89(4):387-399.

17. Perseghin G, et al. Regulation of glucose homeostasis in humans with denervated livers. J Clin Invest. 1997; 100(4):931-941.

18. Moore MC, Satake S, Baranowski B, Hsieh PS, Neal DW, Cherrington AD. Effect of hepatic denervation on peripheral insulin sensitivity in conscious dogs. Am J Physiol Endocrinol Metab. 2002; 282(2):E286-E296.

19. Sindelar DK, Balcom JH, Chu CA, Neal DW, Cherrington $\mathrm{AD}$. A comparison of the effects of selective increases in peripheral or portal insulin on hepatic glucose production in the conscious dog. Diabetes. 1996;45(11):1594-1604

20. Edgerton DS, et al. Insulin's direct effects on the liver dominate the control of hepatic glucose production. J Clin Invest. 2006;116(2):521-527.

21. Havrankova J, Roth J, Brownstein MJ. Concentrations of insulin and insulin receptors in the brain are independent of peripheral insulin levels. Studies of obese and streptozotocin-treated rodents. J Clin Invest. 1979;64(2):636-642.

22. Bergman RN. New concepts in extracellular signaling for insulin action: the single gateway hypothesis. Recent Prog Horm Res. 1997;52:359-385.

23. Mittelman SD, Fu YY, Rebrin K, Steil G, Bergman RN. Indirect effect of insulin to suppress endogenous glucose production is dominant, even with hyperglucagonemia. J Clin Invest. 1997; 100(12):3121-3130.

24. Sindelar DK, Chu CA, Rohlie M, Neal DW, Swift $\mathrm{LL}$, Cherrington AD. The role of fatty acids in mediating the effects of peripheral insulin on hepatic glucose production in the conscious dog. Diabetes. 1997;46(2):187-196.

25. Ramnanan CJ, et al. Molecular characterization of insulin-mediated suppression of hepatic glucose production in vivo. Diabetes. 2010;59(6):1302-1311.

26. Moore MC, et al. Disposition of a mixed meal by the conscious dog. Am J Physiol. 1994; 266(4 pt 1):E666-E675.

27. Bishop JS, Larner J. Rapid activation-inactivation of liver uridine diphosphate glucose-glycogen transferase and phosphorylase by insulin and glucagon in vivo. J Biol Chem. 1967;242(6):1354-1356.

28. Moh A, et al. STAT3 sensitizes insulin signaling by negatively regulating glycogen synthase kinase- 3 beta. Diabetes. 2008;57(5):1227-1235

29. Scherer T, et al. Brain insulin controls adipose tissue lipolysis and lipogenesis. Cell Metab. 2011;13(2):183-194.

30. Burgess SC, et al. Cytosolic phosphoenolpyruvate carboxykinase does not solely control the rate of hepatic gluconeogenesis in the intact mouse liver. Cell Metab. 2007;5(4):313-320.

31. Cherrington AD, Moore MC, Sindelar DK, Edgerton DS. Insulin action on the liver in vivo. Biochem Soc Trans. 2007;35(pt 5):1171-1174.

32. Kokubun E, Hirabara SM, Fiamoncini J, Curi R, Haebisch H. Changes of glycogen content in liver, skeletal muscle, and heart from fasted rats. Cell Biochem Funct. 2009;27(7):488-495.

33. Hendrick GK, Frizzell RT, Williams PE, Cherrington AD. Effect of hyperglucagonemia on hepatic glycogenolysis and gluconeogenesis after a prolonged fast. Am J Physiol. 1990;258(5 pt 1):E841-E849.

34. Nuttall FQ, Ngo A, Gannon MC. Regulation of hepatic glucose production and the role of gluconeogenesis in humans: is the rate of gluconeogenesis constant? Diabetes Metab Res Rev. 2008; 24(6):438-458.

35. Strowski MZ, Blake AD. Function and expression of somatostatin receptors of the endocrine pancreas. Mol Cell Endocrinol. 2008;286(1-2):169-179.

36. Brand CL, et al. Role of glucagon in maintenance of euglycemia in fed and fasted rats. Am J Physiol. 1995; 269(3 pt 1):E469-E477.

37. Cherrington AD, Chiasson JL, Liljenquist JE, Lacy WW, Park CR. Control of hepatic glucose output by glucagon and insulin in the intact dog. Biochem Soc Symp. 1978;(43):31-45.

38. Liljenquist JE, et al. Evidence for an important role of glucagon in the regulation of hepatic glucose production in normal man. J Clin Invest. 1977; 59(2):369-374.

39. Javaheri S, Corbett W. Ethanol is a potent inhibitor of canine cerebrospinal fluid production: an acute and reversible effect. Brain Res. 1998;812(1-2):91-96.

40. Burgess SC, et al. Impaired tricarboxylic acid cycle activity in mouse livers lacking cytosolic phosphoenolpyruvate carboxykinase. J Biol Chem. 2004; 279(47):48941-48949.

41. Mari A, Stojanovska L, Proietto J, Thorburn AW. A circulatory model for calculating non-steady-state glucose fluxes. Validation and comparison with compartmental models. Comput Methods Programs Biomed. 2003;71(3):269-281. 